\title{
Influence of Organisational Culture on Supply Chain Resilience: A Power and Situational Strength Conceptual Perspective
}

\author{
James Whiteside ${ }^{1}$ and Samir Dani ${ }^{2, *}$ \\ 1 Huddersfield Business School, University of Huddersfield, Huddersfield HD1 3DH, UK; \\ james.whiteside@hud.ac.uk \\ 2 Keele Business School, Keele University, Keele ST5 5AA, UK \\ * Correspondence: s.dani@keele.ac.uk
}

Received: 2 May 2020; Accepted: 19 June 2020; Published: 7 July 2020

check for updates

\begin{abstract}
The purpose of this paper is to explore how organisational culture, represented by the competing values framework (CVF), and the relationship mechanisms of situational strength and power influence an organisation's approach to supply chain resilience (SCRES). This is a conceptual paper which uses a multi-theoretical approach to create a framework outlining how organisations which possess different characteristics of culture within the CVF will work to achieve SCRES. Secondary analysis of four case examples as discussed in the supply chain and resilience literature are then used to support the development of propositions from this framework in more detail. The paper suggests that 'flexibility focused' cultures will create weaker situational strengths for supply chain partners when managing disruptions, while 'stability focused' cultures will create stronger situational strengths in the same scenarios. 'Internally focused' cultures may use coercive power with supply chain partners when managing disruptions, while 'externally focused' cultures will prefer non-coercive power in the same scenarios. The four case studies from the literature highlight that each type of culture within the CVF can enable an organisation to achieve SCRES. The practical implications of the findings are that managers should take into consideration how their organisation's culture will influence their relationships with supply chain partners, depending on their application of power and situational strength. However, future research is required to empirically test the propositions.
\end{abstract}

Keywords: organisational culture; supply chain resilience; competing values framework; power; situational strength

\section{Introduction}

From a machinery breakdown at a manufacturing plant, through to natural disasters such as the Tohoku earthquake in Japan (Matsuo 2015) and industrial issues such as strike action in the Brazilian trucking industry (Shashi et al. 2020), disruptions of varying impacts and likelihoods impact how supply chains operate on a daily basis. To counteract this, supply chains are required to become more 'resilient' to effectively deal with these disruptions (Sheffi and Rice 2005). A number of researchers have discussed the concepts of resilience in the operational area (Bhamra et al. 2011; Wied et al. 2020). In the supply chain management field, resilience is described as "the adaptive capability of the supply chain to prepare for unexpected events, respond to disruptions, and recover from them by maintaining continuity of operations at the desired level of connectedness and control over structure and function" (Ponomarov and Holcomb 2009, p. 131). Essuman et al. (2020) have considered a number of studies to discuss both operational and supply chain resilience and found that different researchers 
consider resilience from different perspectives; for example, at focal firm level, at supply chain level, supply network, and supply system.

While the volume of literature in this area has increased over the years, the scope of the research requires more breadth and depth (Tukamuhabwa et al. 2015). There are several definitions for SCRES. Two additional definitions considered in this paper are: "the ability of a supply chain to return to normal operating performance, within an acceptable period of time, after being disturbed" (Brandon-Jones et al. 2014); and "In disaster relief supply networks, resilience encompasses conducting preparation, response, and recovery activities for a disaster event" (Day 2014). Ali and Gölgeci (2019) comment that there is a lack of theoretical breadth in supply chain resilience (SCRES) research, and that future studies should look to utilise a number of theories to "explore their complementary characteristics ... and better comprehend the multi-dimensional issues of SCRES" (Ali and Gölgeci 2019, p. 806).

An area of research which has started to receive more attention in the SCRES field is culture. Sheffi and Rice (2005) acknowledge the importance of culture for achieving SCRES, with risk management culture (Soni et al. 2014), national culture (Durach and Wiengarten 2017) and security culture (Williams et al. 2009) all previously being studied in this area. Mello and Stank (2005) explain that organisational culture plays a role in the relationship management between firms across the supply chain, stating that this impacts "the ability to cooperate between firms, share information, risks and rewards, establish long-term relationships and common customer service goals, and integrate across functional areas and key processes" (Mello and Stank 2005, p. 551). One of the most popular theories of organisational culture utilised over the years is the competing values framework (Cameron and Quinn 2011). This framework assesses the different cultural aspects of a firm, including internal/external focus and preference for stability/flexibility, and how these cultural variables affect the overall effectiveness of a firm (Cameron and Quinn 2011). Within SCRES studies, the competing values framework (CVF) has been applied by a few authors (Mandal 2017; Altay et al. 2018; Murphy et al. 2020), but this paper studies this theory in relation to the situational strength theory and power, which is novel.

Richey (2009) suggests that the CVF can be combined with other theories in order to advance research when studying supply chain disasters. Given the link between organisational culture and relationship management highlighted by Mello and Stank (2005) above, the aim of this research is to further understand how the combination of these factors influence approaches to SCRES. Firstly, Gölgeci et al. (2018) propose that power should be linked with cultural theories, such as the CVF, in order to ascertain "the influence of cultural values on power based behaviours" (Gölgeci et al. 2018, p. 285). While Murphy et al. (2020) have combined the concepts of culture and power to explain how supply chain partners behave within supply chain relationships, this paper looks to explore how a second relationship mechanism, situational strength (Mischel 1977), can be linked to both of these factors to influence approaches to SCRES. Masood et al. (2006) have previously linked the CVF with the concept of situational strength, a theory which describes the "implicit or explicit cues provided by external entities regarding the desirability of potential behaviours for the firm" (Meyer et al. 2010, p. 122). As situational strength has received little attention within the supply chain management field (Gligor et al. 2019), this study provides a good opportunity to explore this theory within a SCRES context.

The aim of this research is to understand how organisational culture and the relationship mechanisms of situational strength and power influence the approach to SCRES. The research questions for this paper are given below:

- How does organisational culture influence the use of power to achieve SCRES?

- How does organisational culture influence the use of situational strength to achieve SCRES?

- How do different cultures within the CVF achieve SCRES based on their application of power and situational strength?

This paper intends to create a conceptual model which details how the above variables link together and provide a springboard for future research in this area. Although this work is not empirical, secondary case study analysis is used to highlight these propositions based on existing articles from the 
wider supply chain and resilience literature. The method of secondary analysis is based on the work of Sabet et al. (2017), who use four case studies from the literature to underpin their conceptual model.

The remainder of this paper is structured as follows. After addressing the current application of relationship mechanisms in SCRES, an overview of the competing values framework and its' application in supply chain management is provided. The relationship mechanisms of situational strength and power are then evaluated, with propositions linking these mechanisms to the competing values framework are introduced. Finally, secondary case examples are used to review these propositions in more detail, before discussing the limitations of this paper and avenues for future research.

\section{Supply Chain Resilience and Relationship Management}

Christopher and Peck (2004) explain that resilience should be built into the supply chain, which includes agility to respond to disruptions effectively and working with supply chain partners to manage risks collectively. There are however a number of barriers which organisations face in trying to achieve SCRES, ranging from having a complicated network of supply chain partners to manage, as well as relying on individual suppliers for certain products which can leave the supply chain vulnerable if a disruption does occur (Rajesh 2018). Johnson et al. (2013) highlight the importance of different relationship mechanisms on the ability of organisations to achieve SCRES. Kumar and Anbanandam (2020) suggest from their research study that organisations "can develop and improve supply chain resilience capability by establishing the risk management culture through improving the risk awareness among employees and conducting periodic risk assessment exercises". They highlight the need to create supply chain connectivity and visibility. Collaboration is a key component of any relationship, as firms need to work closely together to minimise any negative impacts of risks and disruptions throughout their supply chain (Faisal et al. 2006; Jüttner and Maklan 2011). Soni et al. (2014) explain that information sharing is another key enabler of SCRES. Information sharing allows for greater levels of communication and connectivity between organisations, whilst simultaneously providing greater visibility across the whole supply chain (Pettit et al. 2013). Prasad et al. (2014) state that the level of integration between firms is dependent on the relationship which exists between them. An example of this is provided by Liu and Lee (2018) through their investigation into integration with third party logistics providers. Their findings show that by integrating more with their supply chain partners, logistics providers can achieve improved levels of SCRES (Liu and Lee 2018). Dubey et al. (2017) find that trust is an essential element of building a resilient supply chain. Trust is created within a supply chain by the actions of a firm to try and build positive relationships, such as collaboration and information sharing as mentioned above (Brusset and Teller 2017).

\section{Competing Values Framework}

The competing values framework is a tool used to explain the characteristics of different types of organisational culture (Cameron and Quinn 2011). Quinn and Rohrbaugh (1983) explain that an organisation's culture consists of several opposing elements, including internal versus external focus, and an orientation towards being either more stable or flexible. These differences in these cultural types means that "flexibility-oriented and control-oriented cultures have differential effects on an organisation's interpretations of external events, and thus differentially affect their responses to the expectations and requirements of the environment" (Liu et al. 2010a, p. 375). The four different types of culture which Cameron and Quinn (2011) describe are adhocracy, clan, hierarchy and market. Adhocratic and clan cultures are seen to be more flexible than hierarchical and market cultures, whilst adhocratic and market cultures (Guo et al. 2014) are found to be more externally focused than clan or hierarchical cultures (Cameron and Quinn 2011). An organisation may first exist as a small start-up business with a dominant adhocracy culture, but this will change as the organisation develops over time to become more clan-dominant, then hierarchical and finally market dominant (Cameron and Quinn 2011). Gregory et al. (2009) discuss the existence of 'balanced' cultures within an organisation, meaning that organisations can utilise elements of all four types of culture within the CVF. Yarborough et al. (2011) 
acknowledge that organisations can consist of a mixture of the cultural types, but with one of these cultures being more evident than the rest.

In terms of application to supply chain management, the CVF has been used in both conceptual and empirical studies. As part of their conceptual paper, Roh et al. (2008) use the taxonomy of supply chain risk proposed by Lee (2002) to align these four different types of organisational cultures to specific supply chain strategies. For example, the authors propose that organisations with adhocracy cultures will experience both high supply and demand uncertainty and would be best to adopt agile supply chain practices to adapt to change (Roh et al. 2008).

Different perspectives exist in the academic literature in terms of the CVF characteristics and their approach to working across supply chain boundaries. Cao et al. (2015) found evidence to show that clan, adhocracy and market cultures are positively associated with supply chain integration. Yunus and Tadisina (2016) explain that organisations which are more externally oriented, such as in market and adhocracy cultures, are better placed to effectively collaborate with firms across their supply chains. Miao et al. (2012) also found that clan culture can positively impact the attitude towards sustainability within supply chains. One advantage that organisations with hierarchical cultures have is that their stability makes them more reliable, meaning that other members of the supply chain find them more trustworthy (Sambasivan and Yen 2010). On the other hand, organisations with a more dominant hierarchical culture achieve lower levels of supply chain integration due to their rigidity when dealing with external partners (Braunschiedel et al. 2010).

In the context of SCRES, Mandal (2017) has applied the CVF to study resilience in healthcare supply chains. In this study, Mandal (2017) suggests that culture influences collaboration, information sharing, and utilisation of capabilities such as technology and learning in relation to SCRES. According to Mandal (2017), organisational culture could enable SCRES in adhocracy, market, and clan cultures; whilst hierarchical cultures may find it difficult to effectively react to uncertainty due to their procedure driven and complex structure. In a humanitarian supply chain setting, Altay et al. (2018) used the CVF to determine that culture has an influence on agility and SCRES. They found that the stability elements of culture within the CVF enable firms to better plan for disruptions, whilst the flexible elements of culture within the CVF enable firms to be able to react effectively in the wake of disruptions (Altay et al. 2018).

\section{Situational Strength}

In terms of how operational relationships are managed within different cultures, Masood et al. (2006) explain that 'situational strength' will be influenced by the organisations dominant culture within the CVF (Masood et al. 2006). Mischel (1977) proposes that in strong situations, the needs of the situation will guide how an individual is expected to act. Examples of strong situations are the need to stop in a car at a red traffic light and proceed at a green traffic light (Mischel 1977). Meyer et al. (2010) explain that a strong situation provides consistent and clear guidance on how an individual should act, constrains an individual's personal decision making and provides consequences for not behaving as expected. In weaker situations, factors such as the personality of the individual and the resources they have available to them will have a much greater influence on how that person reacts, such as whether to stop or proceed at an amber traffic light (Mischel 1977). In weaker situations, the attitude and perception of the individual in a given situation is much more important (Meyer et al. 2014). Both types of situation strength are important for different contexts and it is essential to understand this link.

Linked to the theory of transformational leadership, Masood et al. (2006) propose that leaders within adhocracy and clan cultures will create weaker situations for employees, meaning that they have greater levels of flexibility in their decision making. Within hierarchy and market cultures, leaders will create stronger situations for employees and therefore be more controlling over their behaviour. 


\section{Power}

Cox (2004) states that there are different types of relationship which exist within supply chains, depending on the level of collaboration and co-operation between supply chain partners. Power is a key, if somewhat overlooked, component of these relationships (Maloni and Benton 2000). Maloni and Benton (2000) discuss supply chain relationships from the aspect of power types as introduced by French and Raven (1959): reward, coercion, expert, referent and legitimate power. Huo et al. (2019) explain that these power types can be separated into two categories, coercive (reward and coercive) and non-coercive (expert, referent and legitimate). Coercive power is defined as "one party's explicit attempts to exert control over partners through negative (both carrot and stick) actions", whilst non-coercive power is defined "one party's attempt to promote desired behaviour in its partners through positive actions such as providing assistance or supportive activities" (Huo et al. 2019, p. 4). While control is the main mechanism used by a focal organisation to establish coercive power over a partner, non-coercive power means that the partner is given the opportunity to use its capabilities in order to work with, and not for, the focal firm (Zhao et al. 2008). Three power sources: non-mediated, coercive-mediated and reward-mediated power are considered within the supply chain by Liu et al. (2015).

In most supply chains, there is generally a focal firm which co-ordinates their operations with other less powerful firms (Zelbst et al. 2009). Wang et al. (2016) note that the types of coercive or non-coercive power which exist between organisations will impact the nature of supply chain relationships. In supplier relationships, "the use of coercive power depends on having such power, and one side's source of power is the other side's dependence resulting from an imbalance of resources" (Liu et al. 2010b, p. 9). Restricting the amount of information, resources and capabilities shared with a supplier can benefit buyers who wish to have more control over their suppliers (Sanfiel-Fumero et al. 2012). However, organisations which have the ability to enforce coercive power over their suppliers, but choose not to, are found to have better relationships with these partners (Huo et al. 2019) and achieve higher levels of supply chain performance (He et al. 2013). Cai et al. (2013) explain while sharing knowledge with suppliers can prove positive for a buying firm, they must be cautious of suppliers acquiring knowledge which they can use as a bargaining tool within their relationship. The pressures of the environment that a supply chain operates in will also affect how power is applied between firms (Cheng 2011). The implication for this is that culture will determine the power dynamics within supply chain relationships, which will ultimately have an influence on supply chain performance and resilience.

\section{Methodology for Building a Conceptual Framework}

The methodology adopted in the paper is a qualitative methodology to explore the SCRES domain using a multi-theoretic approach. Since this domain is not well researched, this study will aim to develop an understanding of the multi theoretic relationships. Based on the discussion above, we develop propositions that link organisational culture to SCRES, through the relationship mechanisms of situational strength and power. As the application of situational strength and power tends to stem from the focal firm in a relationship (Zelbst et al. 2009), we consider the organisational culture of the focal firm within the supply chain to influence the overall resilience of the supply chain. Proposals linking each of these concepts together are discussed below. The methodology also adopts the secondary case analysis procedure from Dani and Deep (2010) and Sabet et al. (2017), to provide support for developing the framework and propositions.

\subsection{Competing Values Framework and Situational Strength}

Based on the work of Masood et al. (2006) relating to the competing values framework, it is proposed that different types of situational strength will be influenced by an organisations' culture. For the purpose of this study, as opposed to solely applying to within-firm relationships, the antecedents of situational strength can be abstracted (Wacker 2008) to explain the relationships between a focal 
organisation and its partners within a supply chain. In a similar way to national cultures influencing the behaviour of citizens (Gelfand and Lun 2013), the focal organisation within a supply chain can influence the actions of other organisations within the chain. In turn, the types of situations provided by a focal organisation (Meyer et al. 2010) will depend on the focal firms' own culture.

Based on the work of Masood et al. (2006), we propose that flexibility dominant focal organisations (adhocracy and clan) will provide weaker situations for supply chain partners, while stability dominant focal organisations (hierarchy and market) will provide stronger situations for other firms within a supply chain when managing SCRES.

P1-Adhocracy dominant organisations create 'weaker situational strength' for supply chain partners when managing SCRES.

P2-Clan dominant organisations create 'weaker situational strength' for supply chain partners when managing SCRES.

P3-Hierarchy dominant organisations create 'stronger situational strength' for supply chain partners when managing SCRES.

P4-Market dominant organisations create 'stronger 'situational strength' for supply chain partners when managing SCRES.

\subsection{Competing Values Framework, Power and Situational Strength}

The two main types of power which have been categorised in the literature are coercive and non-coercive (Huo et al. 2019). The use of coercive power within supplier relationships implies that a focal organisation is much more controlling of the other, uses stringent rules and regulations to enforce this control, and is reluctant to work collaboratively with suppliers (Liu et al. 2010b). Linking this form of power to the CVF, this aligns itself more towards internally dominant focal organisations (clan and hierarchy), due to their internal focus and being less willing to work with external partners (Cameron and Quinn 2011; Liu et al. 2010a). Non-coercive power on the other hand allows the focal organisation to work collaboratively with suppliers, through means such as information sharing, integration, and trust (Cheng 2011; Cadden et al. 2015). Linking this form of power to the CVF, this aligns itself more towards externally dominant focal organisations (adhocracy and market), due to their external focus and being more willing to work with their supply chain partners (Cameron and Quinn 2011; Liu et al. 2010a). We propose,

P5-Adhocracy dominant organisations will use non-coercive power in supplier relationships to achieve SCRES.

P6-Market dominant organisations will use non-coercive power in supplier relationships to achieve SCRES.

P7-Clan dominant organisations will use coercive power in supplier relationships to achieve SCRES.

P8-Hierarchy dominant organisations will use coercive power in supplier relationships to achieve SCRES.

\subsection{Organisational Culture and SCRES}

In terms of achieving SCRES, Mandal (2017) explains that firms with adhocracy, clan and market cultures enable SCRES, whilst hierarchical cultures do not. Adhocracy, clan and market cultures achieve resilience through means such as information sharing and collaboration (Mandal 2017). Altay et al. (2018) argues, however, that the stable orientation of hierarchy and market cultures allow firms to be able to plan effectively for disruptions. While some authors explain that hierarchical cultures can have negative impacts on supply chain performance (Braunschiedel et al. 2010; Cao et al. 2015), Sambasivan and Yen (2010) find that the stability that these cultures provide to supply chain partners can help with building relationships. Although there is debate in regard to which type of culture will enable SCRES as shown above, we propose that SCRES can be achieved by all four cultures. However, enabling and achieving SCRES will depend on the interaction of situational strength and power type. 


\subsection{The Proposed Framework}

The propositions created above highlight how culture influences SCRES through the use of situational strength and power in managing supply chain relationships. Based on the propositions discussed earlier, we propose the following frameworks that consider the dynamics between the four theories (CVF, Power, Situational Strength, and SCRES) to determine how different cultures can enable SCRES.

Figure 1 depicts the relationship between CVF and situational strength as discussed in Section 6.1. This shows the relationship as proposed in P1-P4.

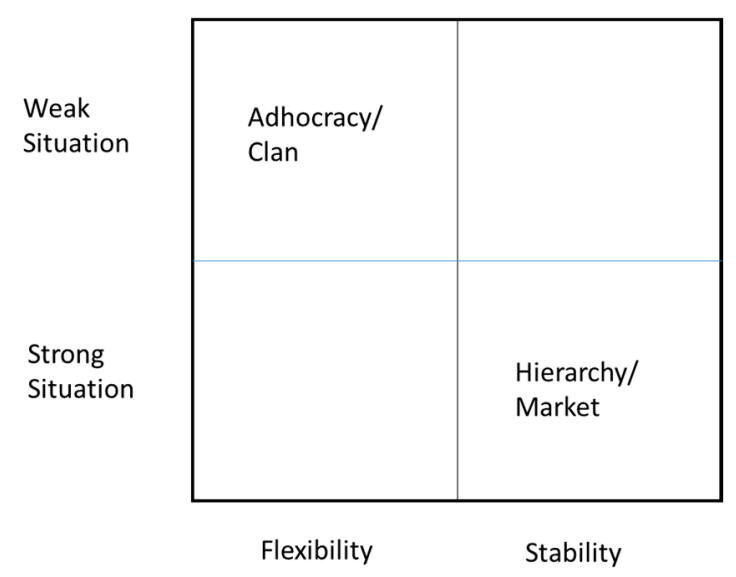

Figure 1. A conceptual framework linking the different cultures within the competing values framework (CVF) to situational strength.

Figure 2 uses the propositions in Section 6.1 and conceptualizes the discussion in Sections 6.2 and 6.3 to depict how power types play a role with CVF and situational strength to enable SCRES.

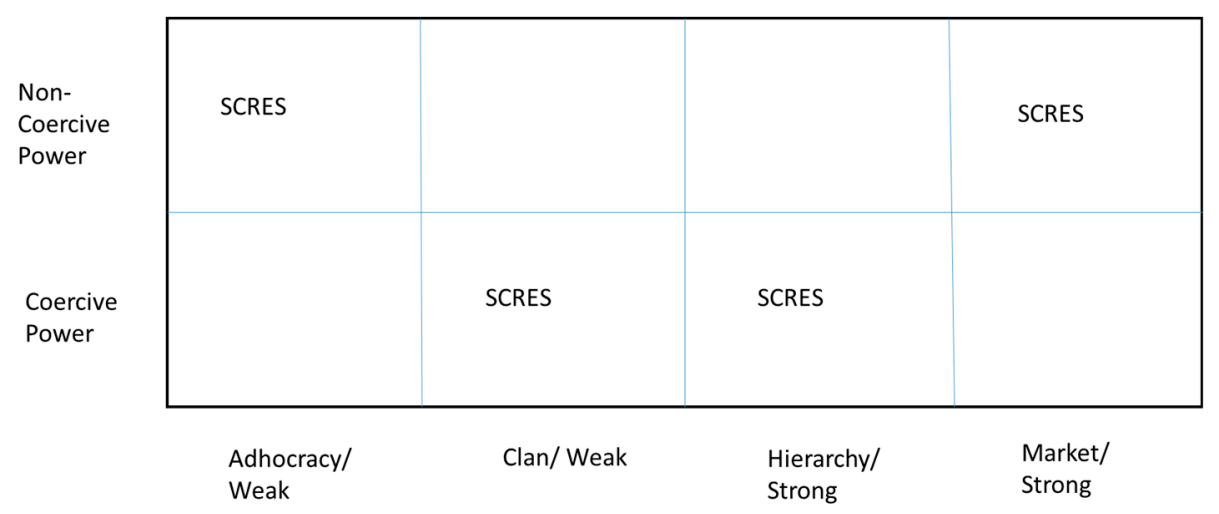

Figure 2. A conceptual framework linking the power types and organisational cultural context to supply chain resilience (SCRES).

Figure 3 brings together the proposed frameworks in Figures 1 and 2 to depict a framework which provides more insight into individual organisational context and the ability of the organisation to create SCRES using power types and situational strength. The framework uses the terms and definitions as per CVF, situational strength, power, and SCRES. The framework is divided into four quadrants.

Quadrant I: Depicts an externally focused organisation with characteristics of flexibility. This type of organisation will create a weak situational strength for the supply chain relationship and use non-coercive power. These organisations will achieve SCRES by working closely with their supply chain partners. 
Quadrant II: Depicts an internally focused organisation with characteristics of flexibility. This type of organisation will create a weak situational strength for the supply chain relationship but use coercive power to monitor performance. These organisations will achieve SCRES by providing supply chain partners with some decision-making flexibility but will be tough on non-conformance.

Quadrant III: Depicts an internally focused organisation with characteristics of stability. Hierarchical and rules based in approach. This type of organisation will create a strong situational strength for the supply chain relationship and use coercive power. These organisations will achieve SCRES by setting the operational rules for the supply chain which all partners will have to follow.

Quadrant IV: Depicts an externally focused organisation with characteristics of stability. This type of organisation will create a strong situational strength for the supply chain relationship (setting the rules) but use non-coercive power. These organisations will achieve SCRES by working closely with their supply chain partners, providing support but setting the rules.

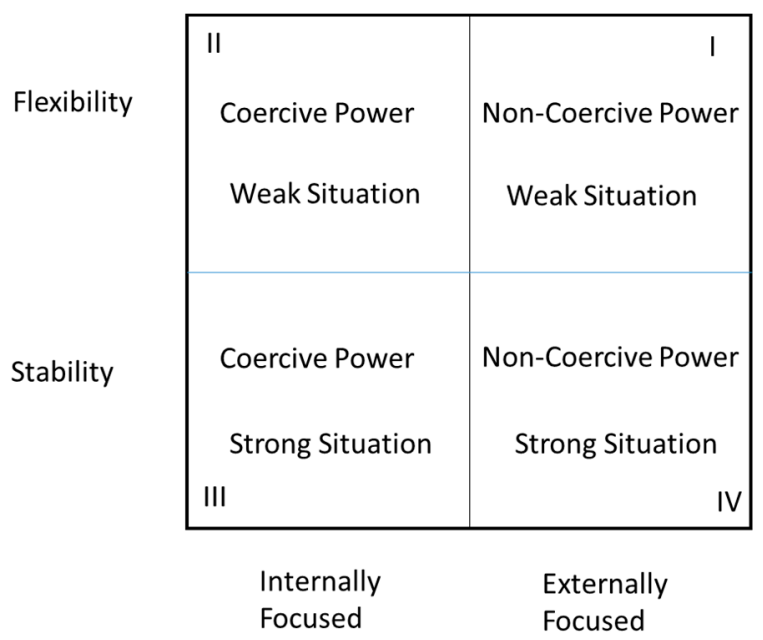

Figure 3. A conceptual framework to achieve SCRES based on organisational culture, power and situation strength.

\section{Case Study Evaluation}

In order to retrospectively discuss the proposed framework, we use case examples which demonstrate the application of power and situational strength: adhocracy (Sullivan-Taylor and Branicki 2011), clan (Ellegaard 2008), hierarchy (Norrman and Jansson 2004) and market cultures (Ergun et al. 2010).

\subsection{Adhocracy Culture-Entrepreneurial SME's}

Sullivan-Taylor and Branicki (2011) studied the practices of Small and Medium Enterprises (SME's) to understand how these organisations achieve resilience. Managers within these organisations explain that there is a limited amount of focus on planning for disasters, with 'muddling through' being seen as the key method of getting through these situations (Sullivan-Taylor and Branicki 2011). These organisations understand the importance of building relationships with external organisations, but they struggle to effectively collaborate with suppliers to be more resilient (Sullivan-Taylor and Branicki 2011). Despite this, these SME's do have certain capabilities, such as agility, which "create an opportunity for rapidity under conditions of extreme uncertainty" (Sullivan-Taylor and Branicki 2011, p. 5574). These capabilities stem from having a lower level of hierarchy in their management structure as opposed to in larger firms (Sullivan-Taylor and Branicki 2011).

Based on the discussion in Section 6, it is inferred that these types of SME's exhibit the characteristics of an adhocratic culture, including an external orientation and a focus on flexibility 
as opposed to planning (Cameron and Quinn 2011). From a situational strength perspective, it is suggested that the SME's do not create strong situations for suppliers in terms of achieving SCRES, as they are more interested in ensuring that their normal operations are carried out effectively (Sullivan-Taylor and Branicki 2011). In terms of power, although the managers discuss the use of collaboration and understand its importance, this practice has not been put in place with their supply base (Sullivan-Taylor and Branicki 2011). This implies that the focal SME in an adhocratic setup would consider using non-coercive power techniques but lacks structure due to a weak situational strength context. Such adhocratic organisations, the SME's described above, are able to achieve SCRES through capabilities such as agility in order to respond quickly when disruptions do occur within the tenets of flexibility and non-coercive power mechanisms.

The case above highlights the positioning in Quadrant I of the framework in Figure 3.

\subsection{Clan Culture-Small Companies}

Ellegaard (2008) investigated the ways in which small businesses manage risks throughout their supply chain through interviews conducted with 11 firms. Flexibility was seen as a vital element by these firms to manage supply chain risks, with reactivity being a key factor in supplier selection (Ellegaard 2008). These firms preferred to use practices such as local sourcing to avoid communication issues with suppliers, with this method of management allowing "them to solve problems ... especially when quality or delivery performance was under threat" (Ellegaard 2008, p. 431). These firms were found to have limited amounts of collaboration with suppliers, with practices such as information sharing, and supplier development avoided by many of the small businesses (Ellegaard 2008). Although the amount of communication with suppliers was limited, these firms tended to adopt a more 'personal' approach when speaking to suppliers in order to try and build better relationships with them (Ellegaard 2008).

It is demonstrated above that these types of SME's exhibit the characteristics of a clan culture, with firms having low levels of external interaction with suppliers and valuing responsiveness in their suppliers (Ellegaard 2008). However, the firms are internally focused in terms of their structures and processes. The use of local sourcing and a personal approach to supplier communications are also practices which would be associated with the 'family' like nature of clan cultures (Cameron and Quinn 2011). From a situational strength perspective, it can be seen that the small businesses tend to have a weak situational strength but more structured than the adhocratic firms. The firm has limited interaction with suppliers when managing supply chain risks (Ellegaard 2008). In terms of power, although the situational strength in weak and firms use local sourcing the processes are structured. Although suppliers can take control of situations if they are required to (Ellegaard 2008), the focal firm will require suppliers to adhere to certain procedures and contractual obligations using coercive power but to a lesser extent than in a hierarchical. Clan-dominant organisations such as the small businesses investigated in the source paper are able to achieve SCRES through a flexible supplier base over which the focal organisation can exert a small amount of power when disruptions do occur.

The case above highlights the positioning in Quadrant II of the framework in Figure 3.

\subsection{Hierarchy Culture-Ericsson}

Norrman and Jansson (2004) studied the risk management practices adopted by Ericsson following a supplier plant fire in 2000, which caused major production and delivery issues in their supply chain. Following this incident, Ericsson put in place a number of organisational changes in order to prevent similar disasters occurring again in the future. A number of roles across the business are now involved with the risk management process, with clear roles and responsibilities outlined for various personnel (Norrman and Jansson 2004). Ericsson have also implemented extensive business continuity plans, which allow them to prepare for any unexpected events in their supply chain. Norrman and Jansson (2004) explained that although the introduced risk management processes allow Ericsson to collaborate more with suppliers, suppliers are required to follow Ericsson's procedures to prepare for disruptions. Examples of these include that the supplier should "maintain a secure sourcing 
plan ... identify a back-up site / resource for each relevant site" and ensure that "key personnel are appointed and reasonably trained on Ericsson's specific product requirements" (Norrman and Jansson 2004, p. 451). When these plans and processes were put in place following another fire several years later, Ericsson was able to minimise the impact to their operations, demonstrating that these risk management processes allowed them to achieve effective greater levels of supply chain resilience (Norrman and Jansson 2004).

It is demonstrated above that Ericsson exhibits the characteristics of a hierarchical culture, by concentrating on its own internal organisational structure and setting out specific rules and regulations for suppliers to follow in regard to risk management (Norrman and Jansson 2004). From a situational strength perspective, it can be seen that Ericsson has created a strong situation for suppliers in terms of achieving SCRES, through their supplier requirements and reporting procedures (Norrman and Jansson 2004). Ericsson utilises coercive power in their supply chain to ensure that their suppliers conform to their requirements and control how suppliers behave (Norrman and Jansson 2004). Hierarchy-dominant organisations such as Ericsson are able to achieve supply chain resilience by being proactive in terms of disruption management and ensuring that their suppliers follow procedures as per the established strong situation.

The case above highlights the positioning in Quadrant III of the framework in Figure 3.

\subsection{Market Culture-Waffle House Restaurants}

Waffle House Restaurants operates stores across the USA, with a large number of stores based in a high-risk hurricane area (Ergun et al. 2010). To combat this, the organisation has developed a detailed hurricane preparation and response plan to ensure that they are able to resume service in their restaurants as soon as possible after a disruption (Ergun et al. 2010). Various functions within Waffle House Restaurants have specific processes and documented procedures to follow when a disruption does occur (Ergun et al. 2010). Waffle House builds relationships with suppliers using information and communications technology and secure additional transport capacity from external partners to ensure a fast response to any affected areas (Ergun et al. 2010). An example of the benefits of these relationships include "developing processes to obtain fuel by establishing relationships with suppliers in the pre-season and making arrangements when storms are imminent" (Ergun et al. 2010, p. 117). In order to aid their suppliers during periods of disruption, Waffle House collaborates with suppliers to provide warning of a hurricane and ensure that suppliers have adequate stock levels to supply restaurants in affected areas (Ergun et al. 2010).

Based on the case information it can be inferred that Waffle House Restaurants exhibits the characteristics of a market culture, with a strong external focus and a characteristic of stability. The firm has control over the disaster response plans through the supply chain by building successful relationships with suppliers (Ergun et al. 2010). From a situational strength perspective, Waffle House creates a strong situation for suppliers in terms of achieving SCRES, through implementation of their response plan when a hurricane is imminent (Ergun et al. 2010). However, Waffle House uses non-coercive power to enable SCRES through proactive behaviour by communicating, collaborating and sharing vital information with suppliers (Ergun et al. 2010). Market-dominant organisations such as Waffle House are able to achieve SCRES by working closely with suppliers to ensure that they are able to deliver stock to affected areas when a hurricane does occur (Ergun et al. 2010).

The case above highlights the positioning in Quadrant IV of the framework in Figure 3.

\section{Discussion}

The current literature on SCRES shows that there is a need to extend the theoretical base of this research area, with a focus on organisational culture. While the relationship mechanisms of collaboration, trust, information sharing, and integration have been studied extensively, there is room to explore other types of relationships from the wider management literature. To address these research gaps, the aim of this paper was to understand how organisational culture is linked to SCRES through the relationship mechanisms of situational strength and power. 
The secondary analysis also showed that organisational culture has an impact on the use of situational strength and power in supply chain relationships. These are theoretical areas which have received relatively little attention from academic researchers in the area of SCRES. Using the CVF as a theoretical base, the authors discussed how the cultural typologies of adhocracy, clan, hierarchy and market create different levels of 'situational strength' for supply chain partners, and also determine the degree of power which exists in the relationships between these parties. A conceptual framework was then created highlighting how these dimensions could be utilized to achieve SCRES. The paper presents a brief retrospective analysis of four case examples from the supply chain and resilience literature to support the development of the framework. However, this presents a start to investigating the relationships depicted in the framework. The theoretical implications of this work demonstrate the effectiveness of using a multi-theoretical approach to provide further understanding of SCRES. While organisational culture, power and SCRES have been studied together, the additional perspective of situational strength provides a deeper level of understanding as to how organisations of different cultures are able to achieve SCRES. As the focal firm within a supply chain will adopt a stronger or weaker degree of situational strength depending on its organisational culture, this in turn has implications for the level of power used in supplier relationships. Since hierarchy and market cultures will create stronger situations for their supply chain partners, this will in turn mean that there will be either a significant increase in the amount of control exhibited towards partners in hierarchical cultures, or a high level of collaboration from organisations with market cultures. The relevance of this insight in the proposed framework is to provide an understanding of how each type of culture (adhocracy, clan, market and hierarchy) can work to achieve SCRES, as opposed to focusing solely on either an organisation's stability/flexibility orientation or internal/external orientation.

The practical implication of this work is that managers need to consider the culture of the organisation which they form a part of, when working with supply chain partners to achieve SCRES. For example, while firms with a market culture will be willing to share information and work more closely with supply chain partners, other more internally focused firms will be less likely to do so and will be more focused on their own organisational activities. This will influence how managers interact with other members of their supply chain, based on the level of situational strength and enforcement of power that is associated with an organisations culture. By understanding the link between the concepts above, managers will be better equipped to deal with supply chain disruptions as and when they occur.

\section{Limitations and Future Research}

There are several limitations of this conceptual paper. Firstly, this framework only considers the culture of the dominant firm within the supply chain. As Cadden et al. (2015) have found, the culture of both the buyer and supplier can have an impact on supply chain performance. The ideas presented above can be used to further examine the relationships which exist between organisations when trying to achieve SCRES.

The propositions within this framework have also not been tested empirically; instead, this paper presents an initial perspective using secondary case examples from the literature. The case examples have been selected as the organisations within them appear to reflect the values of specific cultures within the CVF. In the future it will be useful to carry out a culture assessment in line with the work of Cameron and Quinn (2011). It is important to note that the CVF presents a view of an organisation across the four dimensions with one dominating characteristic. The next steps for future research with regards to this framework are to evaluate the relationships in the framework empirically to determine the role which situational strength and power play in linking organisational culture to SCRES. Researchers can utilize the Organisational Culture Assessment Index (Cameron and Quinn 2011) to evaluate organisational culture, the Situational Strength at Work questionnaire developed by Meyer et al. (2014) to measure different characteristics of situational strength and the work of Huo et al. (2019) to measure both coercive and non-coercive power. 
This framework could be applied to other areas of supply chain management, such as strategy, performance and green supply chain management. Organisational culture, situational strength and power may play a key part in all these areas. Applying the principles from this paper in different supply chain contexts could provide new research directions.

Author Contributions: Conceptualization, S.D. and J.W.; methodology, J.W. and S.D.; writing—original draft preparation, J.W.; writing-review, editing, modifying, S.D.; supervision, S.D. All authors have read and agreed to the published version of the manuscript.

Funding: This research received no external funding.

Conflicts of Interest: The authors declare no conflict of interest.

\section{References}

Ali, Imran, and Ismail Gölgeci. 2019. Where is supply chain resilience research heading? A systematic and co-occurrence analysis. International Journal of Physical Distribution \& Logistics Management 49: 793-815. [CrossRef]

Altay, Nnezih, Angappa Gunasekaran, Rameshwar Dubey, and Stephen J. Childe. 2018. Agility and resilience as antecedents of supply chain performance under moderating effects of organizational culture within the humanitarian setting: A dynamic capability view. Production Planning \& Control 29: 1158-74. [CrossRef]

Bhamra, Ran, Samir Dani, and Kevin Burnard. 2011. Resilience: The concept, a literature review and future directions. International Journal of Production Research 49: 5375-93. [CrossRef]

Brandon-Jones, Emma, Brian Squire, Chad W. Autry, and Kenneth J. Petersen. 2014. A contingent resource-based perspective of supply chain resilience and robustness. Journal of Supply Chain Management 50: 55-73. [CrossRef]

Braunschiedel, Michael J., Nallan C. Suresh, and Alicia D. Boisnier. 2010. Investigating the impact of organizational culture on supply chain integration. Human Resource Management 49: 883-911. [CrossRef]

Brusset, Xavier, and Christoph Teller. 2017. Supply chain capabilities, risks, and resilience. International Journal of Production Economics 184: 59-68. [CrossRef]

Cadden, Trevor, Donna Marshall, Paul Humphreys, and Ying Yang. 2015. Old habits die hard: Exploring the effect of supply chain dependency and culture on performance outcomes and relationship satisfaction. Production Planning \& Control 26: 53-77. [CrossRef]

Cai, Shun, Mark Goh, Robert de Souza, and Gang Li. 2013. Knowledge sharing in collaborative supply chains: Twin effects of trust and power. International Journal of Production Research 51: 2060-76. [CrossRef]

Cameron, Kim S., and Robert E. Quinn. 2011. Diagnosing and Changing Organisational Culture: Based on the Competing Values Framework, 3rd ed. San Francisco: John Wiley and Sons, Inc.

Cao, Zhi, Baofeng Huo, Yuan Li, and Xiande Zhao. 2015. The impact of organizational culture on supply chain integration: A contingency and configuration approach. Supply Chain Management: An International Journal 20: 24-41. [CrossRef]

Cheng, Jao-Hong. 2011. Inter-organizational relationships and information sharing in supply chains. International Journal of Information Management 31: 374-84. [CrossRef]

Christopher, Martin, and Helen Peck. 2004. Building the Resilient Supply Chain. The International Journal of Logistics Management 15: 1-14. [CrossRef]

Cox, Andrew. 2004. The art of the possible: Relationship management in power regimes and supply chains. Supply Chain Management: An International Journal 9: 346-56. [CrossRef]

Dani, Samir, and Aman Deep. 2010. Fragile food supply chains: Reacting to risks. International Journal of Logistics Research and Applications 13: 395-410. [CrossRef]

Day, Jamison M. 2014. Fostering emergent resilience: The complex adaptive supply network of disaster relief. International Journal of Production Research 52: 1970-88. [CrossRef]

Dubey, Rameshwar, Angappa Gunasekaran, Stephen J. Childe, Athanasios Papadopoulos, Constantin Blome, and Zongwe Luo. 2017. Antecedents of Resilient Supply Chains: An Empirical Study. IEEE Transactions on Engineering Management 66: 8-19. [CrossRef]

Durach, Christian F., and Frank Wiengarten. 2017. Exploring the impact of geographical traits on the occurrence of supply chain failures. Supply Chain Management: An International Journal 22: 160-71. [CrossRef] 
Ellegaard, Chris. 2008. Supply risk management in a small company perspective. Supply Chain Management: An International Journal 13: 425-34. [CrossRef]

Ergun, Ozlem, Jessica L. Heier Stamm, Pinar Keskinocak, and Julie L. Swann. 2010. Waffle House Restaurants hurricane response: A case study. International Journal of Production Economics 126: 111-20. [CrossRef]

Essuman, Dominic, Nathaniel Boso, and Jonathan Annan. 2020. Operational resilience, disruption, and efficiency: Conceptual and empirical analyses. International Journal of Production Economics 229. [CrossRef]

Faisal, Mohd Nishat, D. K. Banwet, and Ravi Shankar. 2006. Supply chain risk mitigation: Modeling the enablers. Business Process Management Journal 12: 535-52. [CrossRef]

French, John R. P., and Bertram Raven. 1959. The bases of social power. In Group Dynamics. Edited by D. Cartwright and A. Zander. New York: Harper \& Row.

Gelfand, Michele J., and Janetta Lun. 2013. The culture of the situation: The role of situational strength in cultural systems. Asian Journal of Social Psychology 16: 34-38. [CrossRef]

Gligor, David M., Siddik Bozkurt, Ivan Russo, and Ayman Omar. 2019. A look into the past and future: Theories within supply chain management, marketing and management. Supply Chain Management: An International Journal 24: 170-86. [CrossRef]

Gölgeci, Ismail, William H. Murphy, and David A. Johnston. 2018. Power-based behaviors in supply chains and their effects on relational satisfaction: A fresh perspective and directions for research. European Management Journal 36: 278-87. [CrossRef]

Gregory, Brian T., Stanley G. Harris, Achilles A. Armenakis, and Christopher L. Shook. 2009. Organizational culture and effectiveness: A study of values, attitudes, and organizational outcomes. Journal of Business Research 62: 673-79. [CrossRef]

Guo, Chiquan, Yong J. Wang, and Ashley Metcalf. 2014. How to calibrate conventional market-oriented organizational culture in 21st century production-centered firms? A customer relationship perspective. International Journal of Production Economics 156: 235-45. [CrossRef]

He, Qile, Abby Ghobadian, and David Gallear. 2013. Knowledge acquisition in supply chain partnerships: The role of power. International Journal of Production Economics 141: 605-18. [CrossRef]

Huo, Baofeng, Min Tian, Yu Tian, and Qiyuan Zhang. 2019. The dilemma of inter-organizational relationships: Dependence, use of power and their impacts on opportunism. International Journal of Operations E Production Management 39: 2-23. [CrossRef]

Johnson, Noel, Dominic Elliot, and Paul R. Drake. 2013. Exploring the role of social capital in facilitating supply chain resilience. Supply Chain Management: An International Journal 18: 324-36. [CrossRef]

Jüttner, Uta, and Stan Maklan. 2011. Supply chain resilience in the global financial crisis: An empirical study. Supply Chain Management: An International Journal 16: 246-59. [CrossRef]

Kumar, Siva, and Ramesh Anbanandam. 2020. Impact of risk management culture on supply chain resilience: An empirical study from Indian manufacturing industry. Proceedings of the Institution of Mechanical Engineers, Part O, Journal of Risk and Reliability 234: 246-59. [CrossRef]

Lee, H. L. 2002. Aligning Supply Chain Strategies with Product Uncertainties. California Management Review 44: 105-19. [CrossRef]

Liu, Chiung-Lin, and Ming-Yu Lee. 2018. Integration, supply chain resilience, and service performance in third-party logistics providers. The International Journal of Logistics Management 29: 5-21. [CrossRef]

Liu, Hefu, Weiling Ke, Kwok Kee Wei, Jibao Gu, and Huaping Chen. 2010a. The role of institutional pressures and organizational culture in the firm's intention to adopt internet-enabled supply chain management systems. Journal of Operations Management 28: 372-84. [CrossRef]

Liu, Yi, Yuan Li, and Leinan Zhang. 2010b. Control mechanisms across a buyer-supplier relationship quality matrix. Journal of Business Research 63: 3-12. [CrossRef]

Liu, Hefu, Weiling Ke, Kwok Kee Wei, and Zhengsheng Hua. 2015. Influence of power and trust on the intention to adopt electronic supply chain management in China. International Journal of Production Research 53: 70-87. [CrossRef]

Maloni, Michael, and W. C. Benton. 2000. Power influences in the supply chain. Journal of Business Logistics 21: 49-73.

Mandal, Santanu. 2017. The influence of organizational culture on healthcare supply chain resilience: Moderating role of technology orientation. Journal of Business \& Industrial Marketing 32: 1021-37. [CrossRef] 
Masood, S. A., Samir S. Dani, Neil D. Burns, and Chris J. Backhouse. 2006. Transformational leadership and organizational culture: The situational strength perspective. Proceedings of the Institution of Mechanical Engineers, Part B: Journal of Engineering Manufacture 220: 941-49. [CrossRef]

Matsuo, Hirofumi. 2015. Implications of the Tohoku earthquake for Toyota's coordination mechanism: Supply chain disruption of automotive semiconductors. International Journal of Production Economics 161: 217-27. [CrossRef]

Mello, John E., and Theodore P. Stank. 2005. Linking firm culture and orientation to supply chain success. International Journal of Physical Distribution \& Logistics Management 35: 542-54. [CrossRef]

Meyer, Rustin D., Reeshad S. Dalal, and Richard Hermida. 2010. A Review and Synthesis of Situational Strength in the Organizational Sciences. Journal of Management 36: 121-40. [CrossRef]

Meyer, Rustin D., Reeshad S. Dalal, Irwin J. Jose, Richard Hermida, Tiffani R. Chen, Ronald P. Vega, Charlie K. Brooks, and Vivek P. Khare. 2014. Measuring Job-Related Situational Strength and Assessing Its Interactive Effects with Personality on Voluntary Work Behavior. Journal of Management 40: 1010-41. [CrossRef]

Miao, Zhaowei, Shun Cai, and Di Xu. 2012. Exploring the antecedents of logistics social responsibility: A focus on Chinese firms. International Journal of Production Economics 140: 18-27. [CrossRef]

Mischel, Walter. 1977. The interaction of person and situation. In Personality at the Crossroads: Current Issues in Interactional Psychology. Edited by D. Magnusson and N. S. Endler. Hillsdale: Lawrence Erlbaum, pp. 333-52.

Murphy, William H., Ismail Gölgeci, and David A. Johnston. 2020. Power-based behaviors between supply chain partners of diverse national and organizational cultures: The crucial role of boundary spanners' cultural intelligence. Journal of Business $\mathcal{E}$ Industrial Marketing 35: 204-18.

Norrman, Andreas, and Ulf Jansson. 2004. Ericsson's proactive supply chain risk management approach after a serious sub-supplier accident. International Journal of Physical Distribution \& Logistics Management 34: 434-56. [CrossRef]

Pettit, Timothy J., Keely L. Croxton, and Joseph Fiksel. 2013. Ensuring Supply Chain Resilience: Development and Implementation of an Assessment Tool. Journal of Business Logistics 34: 46-76. [CrossRef]

Ponomarov, Serhiy Y., and Mary C. Holcomb. 2009. Understanding the concept of supply chain resilience. The International Journal of Logistics Management 20: 124-43. [CrossRef]

Prasad, Sameer, Hung-Chung Su, Nezih Altay, and Jasmine Tata. 2014. Building disaster-resilient micro enterprises in the developing world. Disasters 39: 447-66. [CrossRef]

Quinn, Robert E., and John Rohrbaugh. 1983. A Spatial Model of Effectiveness Criteria: Towards a Competing Values Approach to Organizational Analysis. Management Science 29: 363-77. [CrossRef]

Rajesh, Rajagopal. 2018. Measuring the barriers to resilience in manufacturing supply chains using Grey Clustering and VIKOR approaches. Measurement 126: 259-73. [CrossRef]

Richey, R. Glenn, Jr. 2009. The supply chain crisis and disaster pyramid, A theoretical framework for understanding preparedness and recovery. International Journal of Physical Distribution and Logistics Management 39: 619-28. [CrossRef]

Roh, James Jungbae, Paul Hong, and Youngsoo Park. 2008. Organizational culture and supply chain strategy: A framework for effective information flows. Journal of Enterprise Information Management 21: 361-76. [CrossRef]

Sabet, Ehsan, Nahid Yazdani, and Sander De Leeuw. 2017. Supply chain integration strategies in fast evolving industries. The International Journal of Logistics Management 28: 29-46. [CrossRef]

Sambasivan, Murali, and Ching Nget Yen. 2010. Strategic alliances in a manufacturing supply chain: Influence of organizational culture from the manufacturer's perspective. International Journal of Physical Distribution $\mathcal{E}$ Logistics Management 40: 456-74. [CrossRef]

Sanfiel-Fumero, Maria. A., Angel Martin Ramos-Dominguez, and Juan R. Oreja-Rodriguez. 2012. The configuration of power in vertical relationships in the food supply chain in the Canary Islands: An approach to the implementation of food traceability. British Food Journal 114: 1128-56. [CrossRef]

Shashi, Piera Centobelli, Roberto Cerchione, and Myriam Ertz. 2020. Managing supply chain resilience to pursue business and environmental strategies. Business Strategy and the Environment 29: 1215-46. [CrossRef]

Sheffi, Yossi, and James B. Rice. 2005. A Supply Chain View of the Resilient Enterprise. MIT Sloan Management Review 47: 41-48.

Soni, Umang, Vipul Jain, and Sameer Kumar. 2014. Measuring supply chain resilience using a deterministic modeling approach. Computers $\mathcal{E}$ Industrial Engineering 74: 11-25. [CrossRef] 
Sullivan-Taylor, Bridgette, and Layla Branicki. 2011. Creating resilient SMEs: Why one size might not fit all. International Journal of Production Research 49: 5565-79. [CrossRef]

Tukamuhabwa, Benjamin R., Mark Stevenson, Jerry Busby, and Marta Zorzini. 2015. Supply chain resilience: Definition, review and theoretical foundations for further study. International Journal of Production Research 53: 5592-623. [CrossRef]

Wacker, John G. 2008. A conceptual understanding of requirements for theory building research: Guidelines for scientific theory building. Journal of Supply Chain Management 44: 5-15. [CrossRef]

Wang, Bill, Paul Childerhouse, Yuanfei Kang, Baofeng Huo, and Sanjay Mathrani. 2016. Enablers of supply chain integration: Interpersonal and interorganizational relationship perspectives. Industrial Management $\mathcal{E}$ Data Systems 116: 838-55. [CrossRef]

Wied, Morten, Josef Oehmen, and Torgier Welo. 2020. Conceptualizing resilience in engineering systems: An analysis of the literature. Systems Engineering 23: 3-13. [CrossRef]

Williams, Zachary, Nicole Ponder, and Chad. W. Autry. 2009. Supply chain security culture: Measure development and validation. The International Journal of Logistics Management 20: 243-60. [CrossRef]

Yarborough, Larry, Neil A. Morgan, and Douglas W. Vorhies. 2011. The impact of product market strategy-organizational culture fit on business performance. Journal of the Academy of Marketing Science 39: 555-73. [CrossRef]

Yunus, Erlinda N., and Suresh K. Tadisina. 2016. Drivers of supply chain integration and the role of organizational culture: Empirical evidence from Indonesia. Business Process Management Journal 22: 89-115. [CrossRef]

Zelbst, Pamela J., Kenneth W. Green Jr., Victoria E. Sower, and Pedro Reyes. 2009. Impact of supply chain linkages on supply chain performance. Industrial Management \& Data Systems 109: 665-82. [CrossRef]

Zhao, Xiande, Baofeng Huo, Barbara B. Flynn, and Jeff Hoi Yan Yeung. 2008. The impact of power and relationship commitment on the integration between manufacturers and customers in a supply chain. Journal of Operations Management 26: 268-388. [CrossRef]

(C) 2020 by the authors. Licensee MDPI, Basel, Switzerland. This article is an open access article distributed under the terms and conditions of the Creative Commons Attribution (CC BY) license (http://creativecommons.org/licenses/by/4.0/). 